\title{
Burning Rate Measurement of KNSu Propellant Obtained by Mechanical Press
}

\author{
Antônio Carlos Foltran¹, Diego Fernando Moro¹, Nicholas Dicati Pereira da Silva1, Ana Eliza Gonçalves \\ Ferreira ${ }^{1}$, Luciano Kiyoshi Araki ${ }^{1}$, Carlos Henrique Marchi ${ }^{1}$
}

\begin{abstract}
The potassium nitrate $\left(\mathrm{KNO}_{3}\right]$ /sucrose $\left(\mathrm{C}_{12} \mathrm{H}_{22} \mathrm{O}_{11}\right)$ propellant, known as $\mathrm{KNSu}$, is traditionally used in rocket studies by amateur groups. Performance tests of $\mathrm{KNSu}$, whose composition is $65 \mathrm{wt} \% \mathrm{KNO}_{3}$ and $35 \mathrm{wt} \%$ $\mathrm{C}_{12} \mathrm{H}_{22} \mathrm{O}_{11}$, cold-manufactured by mechanical press, are presented in this paper. The study determines the behaviour of density $(\rho)$ and burning rate $(r)$ as function of compression pressure $\left(P_{c}\right)$ for the propellant grain manufacturing. Fortyfour samples were prepared and tested, for seven different values of $P_{c}$. It was observed that $\rho$ and $r$ depend on $P_{c}$, according to quadratic polynomial functions, and the mass flux per unit area is a constant.
\end{abstract}

KEYWORDS: Potassium nitrate, Sucrose, KNSu, Experimental rocket motor, Model rocket, Solid propellant.

\section{INTRODUCTION}

The potassium nitrate $\left(\mathrm{KNO}_{3}\right)$ /sucrose $\left(\mathrm{C}_{12} \mathrm{H}_{22} \mathrm{O}_{11}\right)$ propellant, known as $\mathrm{KNSu}$, is traditionally used in rocket studies by amateur groups. Both components are easy to buy, their combustion products are non-toxic and this propellant can produce relatively high specific impulse, with values higher than the ones obtained by black gunpowder commonly used in model rockets (Leslie and Yawn, 2002).

Traditional methods employed in the production of propellant grains involve fusion (recrystallization) process. In this case, both propellant components are grinded and mixed. After, the mixture is heated until the sucrose fusion around the nitrate grains, forming a doughy mixture which can be placed in molds with a proper propellant grain design, and is cooled in sequence (Vyverman, 1978; Nakka, 1984). This methodology produces high density propellant grains (Nakka, 1984); there are, however, risks associated to the propellant combustion by the heating process. Many amateur rocket builders, who use this methodology, consider it secure; nevertheless, it is indispensible the use of equipments that provide a slow and gradual heating process, as well as the control of temperature along the fusion process (Nakka, 1997).

In this paper, however, an alternative methodology for cold manufacturing was studied. It involves the grinding and mixture of components, as well as the preparation of propellant grain by compaction of components in a die with the use of a hydraulic press machine. Cold manufacturing, in different ways, was used by Marchi et al. (1990), Moro (2013) and Thompson (2014). According to Nakka (1997), heated propellant is inherently more hazardous than cool propellant

1.Universidade Federal do Paraná - Departamento de Engenharia Mecânica - Curitiba/PR - Brazil.

Author for correspondence: Luciano Kiyoshi Araki | Universidade Federal do Paraná - Depto. Engenharia Mecânica | Caixa Postal: 19.040 | CEP: $81.531-980$ Curitiba/PR - Brazil | Email: lucaraki@ufpr.br

Received: 10/24/2014 | Accepted: 02/25/2015 
for two reasons: (1) less energy is required to ignite it; and (2) burning rate of hot propellant is much greater, perhaps by a factor of five.

The aim of this paper was to provide the propellant grains production in a simple way, consisting only on grinding and mixing the components, in absence of a heating process. The used security recommendations were basically the ones relative to chemical products manipulation (Wallace, 1995), described by Nakka (1997). Furthermore, a study of how to determine the dependence of density on compression pressure was made, comparing different propellant batches.

\section{METHODOLOGY SAMPLE PREPARATION}

The used propellant components for sample manufacture were potassium nitrate and refined sugar. Each component was milled in an individual mill with rotary blades. Each mill was carried up to $90 \%$ of maximum volume and used by $30 \mathrm{~s}$.

After grinding, the components were stored in individual pots. The chemical composition adjustment was made by measuring the components' masses in a scale with $0.01 \mathrm{~g}$ resolution. The components were then placed in a third hermetic pot and each $100 \mathrm{~g}$ of propellant were manually shaken for $15 \mathrm{~min}$.

Samples present a parallelepipedal shape, with approximately $60 \mathrm{~mm} \times 20 \mathrm{~mm}$ in transversal section and height between 7.8 and $9.4 \mathrm{~mm}$ dependent on the applied compression pressure. All samples were manufactured with $16 \mathrm{~g}$ of powdered components. The experiment consists of nine tests. Each test was composed by five samples, except by the first one, which was made with four samples, totalizing 44 samples. Moreover, the propellants for these nine tests were prepared in batches (i.e. different mixture preparation operations): for tests 1 to 5 , five different propellant batches were prepared; for tests 6 to 9 , only one batch was made.

The applied forces on each sample, for a given test, were 2, 4, 6, 8 and 10 tons-force. Exceptions were: (1) the $1^{\text {st }}$ test, for which one sample was compressed with 3 tons-force, two with 6 tons-force and one with 9 tons-force; and (2) the $6^{\text {th }}$ test, for which all five samples were compressed using 6 tons-force. Because of this, seven nominal pressures were generated for different compression pressures, approximately, equal to 16 , 24, 32, 48, 64, 72 and $80 \mathrm{MPa}$.
The following forces were neglected, since they are relatively small: friction forces of the hydraulic cylinder gasket; the deformation forces related to the return spring of the press hydraulic cylinder; and the friction forces between the punch and the die. Then, considering the pressurized system in equilibrium, the following relation can be applied:

$$
P_{c}=p_{2}=\frac{p_{1} A_{1}}{A_{2}}=\frac{F_{1}}{A_{2}}
$$

where:

$p_{1}$ : pressure inside the hydraulic system; $P_{c}$ or $p_{2}$ : compression pressure; $A_{1}$ and $A_{2}$ : areas of the hydraulic cylinder piston and the sample under compression pressure, respectively; $F_{1}$ : force produced by the pressure of the hydraulic system acting on the piston area.

\section{DENSITY EVALUATION}

After the press process, the samples were removed from the die and cleaned with a cloth in order to remove small detached grains. For each sample, measurements consisted of: length (once), width (at three different positions along the sample length) and thickness (at six different positions along the sample length). These several measurements of width and thickness were made since there were small imperfections in both punch and die.

From the average of all dimension values, it was possible to evaluate the volume of each sample and to obtain the density as a ratio of the measured mass by volume. Since the KNSu samples are: (1) highly hygroscopic and (2) porous, it was preferable to evaluate the volume of each sample in a stereometric form in spite of immersing samples in a liquid, which is a common practice.

The obtained value for density could be compared to the theoretical density $\rho_{t}$, which considers the mass fraction of components and their respective densities as crystalline solids; in other words, it supposes a sample without any porosity, so it stands an upper limit to density to be obtained in tests:

$$
\rho_{t}=\frac{1}{\frac{x_{S U}}{\rho_{S U}}+\frac{x_{K N}}{\rho_{K N}}} \cong 1888 \frac{\mathrm{kg}}{\mathrm{m}^{3}}
$$

where:

$\rho_{K N}$ and $\rho_{S U}:$ density values of potassium nitrate $\left(2,109 \mathrm{~kg} / \mathrm{m}^{3}\right)$ and sucrose $\left(1,581 \mathrm{~kg} / \mathrm{m}^{3}\right)$, respectively; $x_{K N}$ and $x_{S U}$ : mass fractions 
of nitrate and sucrose (fixed as 0.65 and 0.35 , in this work), in this order.

Atmospheric pressure variation was not significant for all tests, so it was irrelevant for analysis. Tests were conducted at atmospheric pressure specially by the fact that, under these conditions, burning rate presents the smallest possible values, what can be of useful for the design of small experimental rocket motors.

Otherwise, room temperature presented variation for all tests: temperature range of 20.0 to $28.0^{\circ} \mathrm{C}$ with average temperature of $25.4^{\circ} \mathrm{C}$. However, for each test, samples were burnt basically at the same room temperature.

\section{BURNING RATE MEASUREMENTS}

All burn out process occurred in open and well ventilated conditions. A $30 \mathrm{fps}$ video camera was placed orthogonally to the flame propagation direction, in order to minimize parallaxes error. A graduated scale was placed in parallel to each sample to enable the measurement of the burning rate at atmospheric conditions in Curitiba, Brazil, $916 \mathrm{~m}$ and $90.6 \mathrm{kPa}$.

All samples presented five faces isolated by a thick layer of glue, which allowed the flame propagation in only one surface. The chosen surface was the one with the smallest area, on which a thin layer of glue was placed. Black gunpowder was placed on it, as a way to guarantee a simultaneous burning ignition of all surface. For safety reasons, a fuse was used to ignite the powder.

The burning rate was obtained by measuring the time interval needed by the flame to cover the distance between two arbitrary points on each sample, namely: from 0 to $20 \mathrm{~mm}$, from 20 to $40 \mathrm{~mm}$, from 40 to $60 \mathrm{~mm}$, from 10 to $30 \mathrm{~mm}$, from 30 to $50 \mathrm{~mm}$, from 0 to $30 \mathrm{~mm}$, from 30 to $60 \mathrm{~mm}$ and from 0 to $60 \mathrm{~mm}$. These sets of points were chosen to verify if the burning rate varies locally at the sample length.

According to Douglass et al. (1972) and Fordham (1980), most solid rocket propellants present a dependence of burning rate on pressure at combustion chamber, which can be described by:

$$
r=a P_{0}^{n}
$$

where:

$r$ : burning rate $(\mathrm{mm} / \mathrm{s})$; $a$ : constant dependent on the propellant $(\mathrm{mm} / \mathrm{MPa} \cdot \mathrm{s}) ; P_{0}$ : pressure at combustion chamber (in $\mathrm{MPa}$ ); $n$ : pressure coefficient (non-dimensional).
However, depending on the author, other sets of measurement units for both pressure and burning rate are employed (Vyverman, 1978; Nakka, 1984; Marchi et al., 1990; Stancato and Miraglia, 1997; Stancato et al., 2000). Nakka (1984, 1997) used Eq. 3 to determine, experimentally, the parameters $a$ and $n$ for KNSu propellant. In this work, only the burning rate for local atmospheric pressure $(90.6 \mathrm{kPa})$ was evaluated.

\section{RESULTS AND DISCUSSION}

Figure 1 shows the burn process of a typical sample. At the two lower frames of Fig. 1, the burning surface is not clear because of the fact that traces of glue layer did not burn as easily as the propellant. Since the flame front is not completely homogeneous, it is difficult to decide exactly when it achieves the initial and final positions. Because of this, each measurement was repeated three times. This strategy allowed the evaluation of uncertainty ranges for the burning rate, based on t-Student distribution with $95 \%$ confidence level. The highest interval was observed for sample 6 and presented $0.20 \mathrm{~mm} / \mathrm{s}$ of amplitude, i.e. $8.4 \%$ with respect to the average of sample 6 .

For some samples, the burning rate was spoiled by the inhibitor inefficiency, which conducted to the burn process in faces other than the one activated by the black gunpowder. Sometimes the flame did not uniformly begin in all activated surface, as expected, or it presented some delay points. When

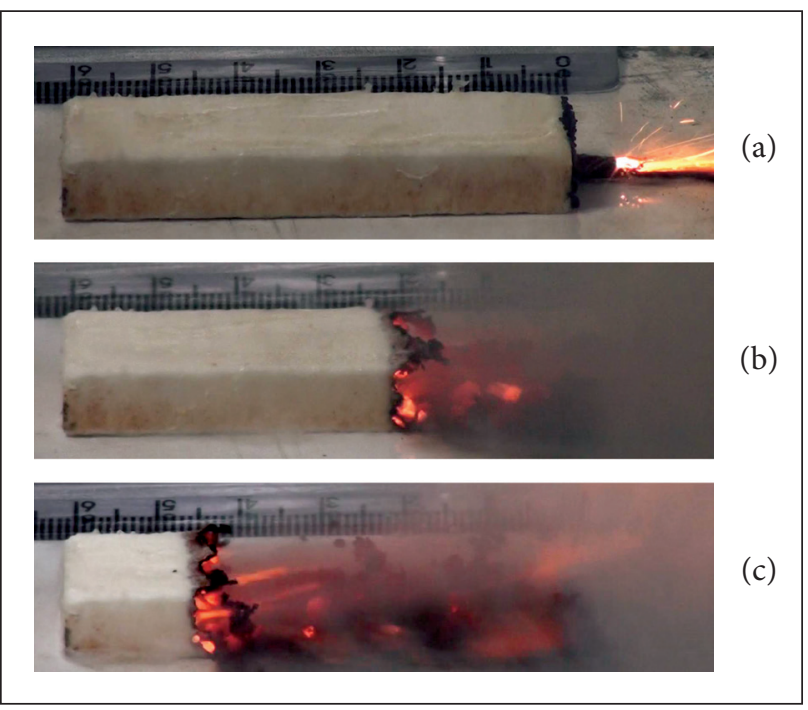

Figure 1. Stages of a sample burn: (a) burn ignition with a fuse; (b) and (c) flame front propagation. 
these phenomena were observed, the flame front propagation was not parallel to the original surface activated with gunpowder. Because of this, from 44 samples, 44 density and only 33 burning rate measurements were obtained. Most problems were observed in initial tests, occasions in which the samples were not efficiently inhibited.

As expected, density values increase with higher compaction pressures. Nevertheless, they are lower than the ones obtained by Nakka (1997) and most ones obtained by Vyverman (1978), which used the fusion process. However, the highest values obtained in this work (at about $80 \mathrm{MPa}$ ) are compatible to the ones observed by Vyverman (1978). The observed values are higher than the ones obtained by using similar production processes, such as presented by Marchi et al. (1990) and one of the authors (Moro, 2013) for rocket motors made using PVC tubes (observing that, in this case, the burn process can occur at slightly higher pressures than the atmospheric one). Marchi et al. (1990) produced the propellant in a similar way to the present in this work, however, without using a hydraulic press machine; in this case, the propellant was mixed with acetone in order to obtain a kind of paste which was poured into the motor, manually pressed and then placed to dry.

From experimental results, three second-order polynomial functions could be adjusted to data: (1) correspondent to tests 1 to 5, i.e. data from five different batches - Eq. 4; (2) correspondent to tests 6 to 9, i.e. data from only one batch - Eq. 5; and (3) the general behaviour of all experimental data - Eq. 6. All polynomials describe the average density $(\rho)$ as function of compaction pressure $\left(P_{c}\right)$ :

Tests 1 to 5 :

$\rho=-0.0356 P_{c}^{2}+7.19 P_{c}+1311$

Tests 6 to 9:

$\rho=-0.0469 P_{c}^{2}+8.11 P_{c}+1288$

All tests:

$\rho=-0.0396 P_{c}^{2}+7.51 P_{c}+1302$

For these three equations, $P_{c}$ and $\rho$ are given, respectively, in $\mathrm{MPa}$ and $\mathrm{kg} / \mathrm{m}^{3}$.

Although the three curves given by Eqs. 4 to 6 are not exactly coincident, they present the same general behaviour. Experimental uncertainties for each group of tests were also evaluated and it was verified that differences among all results are not significant. For each group of batches (1 to 5 and 6 to 9), results are over and under the respective polynomial fit equation. Based on these facts, it was preferable to use the average behaviour of all tests, i.e. Eq. 6.

The behaviour of Eq. 6 can also be graphically seen in Fig. 2, with experimental results for all samples of all tests. Figure 2 also includes results from other authors and the theoretical density, described by Eq. 2.

Tests 6 to 9 were prepared from the same propellant batch; because of this, similar results for these tests were expected. However, these tests also presented a similar behaviour to the first five ones. Test 6, for which all samples were pressed with $48 \mathrm{MPa}$, produced samples with almost the same density values and, because of this, there are several overlying marks of these five samples in Fig. 2.

Values of all samples were grouped according to compaction pressure and, based on $\mathrm{t}$-Student distribution with $95 \%$ confidence level, uncertainty intervals were obtained. They are shown in Fig. 2 and the highest value was observed for the $64 \mathrm{MPa}$ group, for which the amplitude was $180 \mathrm{~kg} / \mathrm{m}^{3}$, i.e. $11 \%$ related to the average value obtained by Eq. 6 . A similar analysis, made only for samples of test 6 , presented an uncertainty interval of $21 \mathrm{~kg} / \mathrm{m}^{3}$, i.e. $1.3 \%$ related to the average value obtained by Eq. 6 .

The burning rate was measured for different regions of samples and the results were analyzed. All samples exhibited small variations in local burning rate; however, none evident behaviour was observed and, because of this, the average burning rate observed from 0 to $60 \mathrm{~mm}$ was used as reference for all analyses of this paper.

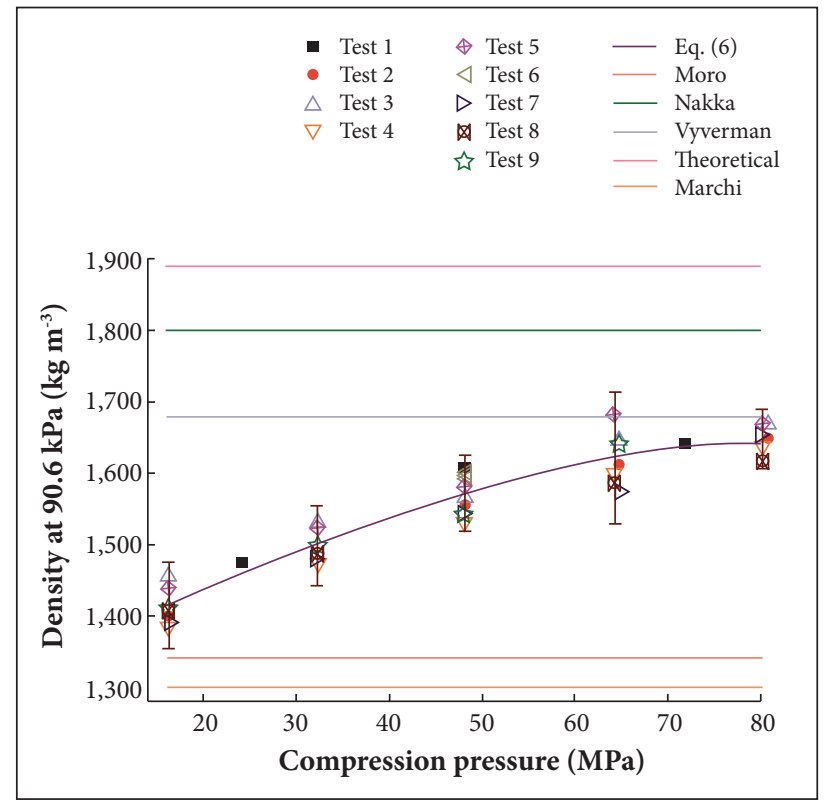

Figure 2. Density versus compression pressure. 
From experimental data, a second-order polynomial function could be adjusted to evaluate the average burning rate $(r)$ as function of compression pressure $\left(P_{c}\right)$ for: $(1)$ tests 1 to $5-$ Eq. 7 ; (2) tests 6 to 9 - Eq. 8; and all experimental data - Eq. 9:

Tests 1 to 5 :

$r=3.15 \times 10^{-5} P_{c}^{2}-9.14 \times 10^{-3} P_{c}+2.88$

Tests 6 to 9:

$r=4.18 \times 10^{-5} P_{c}^{2}-9.38 \times 10^{-3} P_{c}+2.75$

All tests:

$r=5.68 \times 10^{-5} P_{c}^{2}-1.13 \times 10^{-2} P_{c}+2.86$

where:

$P_{c}$ and $r$ are given, respectively, in $\mathrm{MPa}$ and $\mathrm{mm} / \mathrm{s}$.

Although the average burning rate equation correctly predicts all experimental data (including experimental uncertainties), the burning rates present a kind of dependence on the batch: tests conducted with samples from batches 1 to 5 presented higher values for burning rate when compared to tests conducted with the samples from the other batch. It is emphasized, however, that the average behaviour, represented by Eq. 9, predicts well all experimental data.

The confidence intervals shown in Fig. 3 were evaluated based on $t-S t u d e n t$ distribution with $95 \%$ confidence level. The amplitude of the major interval, for all tests, was observed for the sample group with $32 \mathrm{MPa}$ compaction pressure. The obtained

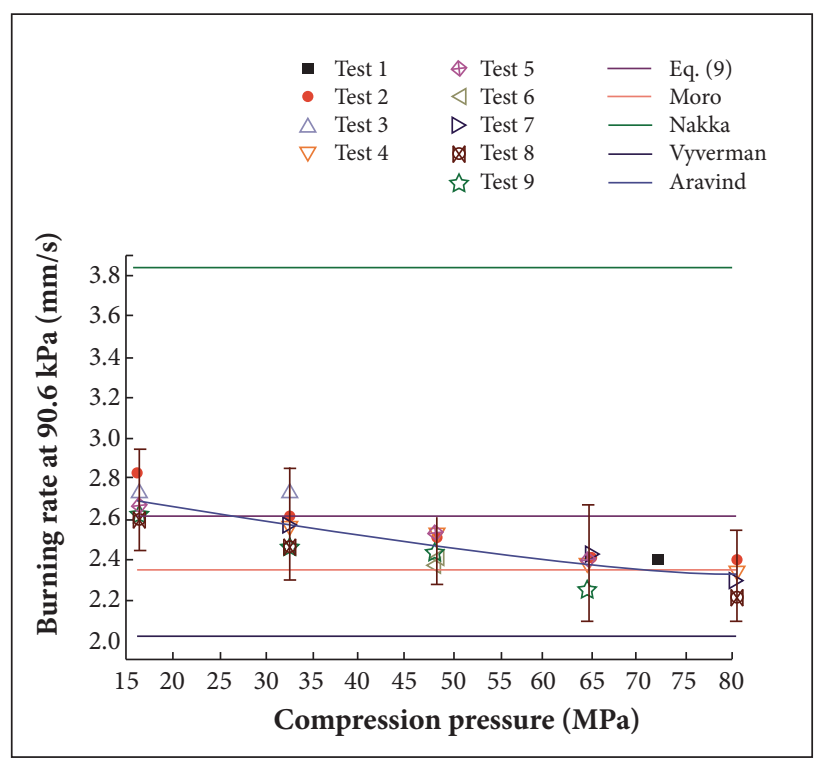

Figure 3. Burning rate versus compression pressure. value was $0.55 \mathrm{~mm} / \mathrm{s}$, which corresponds to $21 \%$ related to the average of such group. The same analysis, however, considering only test $6(48 \mathrm{MPa})$, presents an amplitude of $0.15 \mathrm{~mm} / \mathrm{s}$, i.e. $6.4 \%$ related to the average of test 6 .

Figure 3 also includes results from other authors: Aravind et al. (2013), Moro (2013), Nakka (1984) and Vyverman (1978). As can be seen, the burning rate presents an opposite behaviour compared to density, since it decreases with higher values of compaction pressure. Since the sample preparation in this work takes a different process from Nakka and Vyverman ones, these authors did not study the influence of compression pressure on the burning rate. The observed experimental results, however, are slightly closer to Vyverman's ones than from Nakka's; they are also nearer Aravind's results, which also produced the propellant by a different process, than the one proposed in this work.

Since density and burning rate presents opposite behaviors in relation to compression pressure, it was analyzed how it affects the combustion gases mass flux, which is given by (Sutton and Biblarz, 2010):

$$
\dot{m}=\rho r A_{b}
$$

where:

$A_{b}$ : burn surface area.

The result from burning rate times density can be identified as gases mass flux $(\dot{m})$ per unit burn surface $\left(A_{b}\right)$, which is graphically presented in Fig. 4. In this figure, results of all samples that presented a regular burn process are presented. It was also observed that the gases mass flux per unit of burnt surface presents an average value of $3.83 \mathrm{~kg} /\left(\mathrm{m}^{2} \mathrm{~s}\right)$. It was verified,

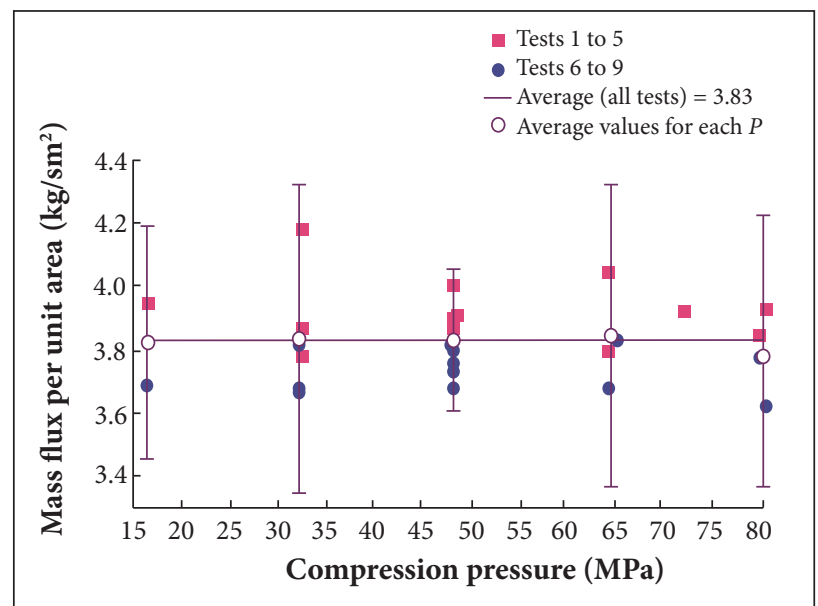

Figure 4. Mass flux per unit area versus compression pressure. 
however, that depending on the batch, this average can slightly change: for tests 1 to 5 , the average is about 3.93, while for tests 6 to 9 , it reduces to 3.74 .

Figure 4 also presents the confidence intervals based on t-Student distribution with $95 \%$ confidence level related to experimental data. The highest interval occurs for $32 \mathrm{MPa}$ pressure and is equal to $0.98 \mathrm{~kg} /\left(\mathrm{m}^{2} \mathrm{~s}\right)$, i.e. it varied $26 \%$ related to the average. In this case, in spite of the average of each group, the average of all samples was employed, since it is nearly independent of the compaction pressure. Even if the averages of different tests are different, considering the experimental uncertainties, the average of all tests correctly represents all data. The confidence intervals for all analyses are coincident and, because of this, one cannot affirm that the three averages are different.

A last important aspect to be mentioned is related to the solid and liquid residua accumulation on the surface where the samples were burnt. Apparently, non-gaseous phases, specially potassium carbonate $\left(\mathrm{K}_{2} \mathrm{CO}_{3}\right)$, can adhere to the rocket nozzle. Figure 5 shows accumulated residua after the burn process of four samples. The quantity of residua was not measured, specially because it was strongly adhered to the plaque surface and a fraction of it was ejected far from the test place. The two samples in the upper portion of Fig. 5 seem to have generated more carbonate residua and the two lower portions, more

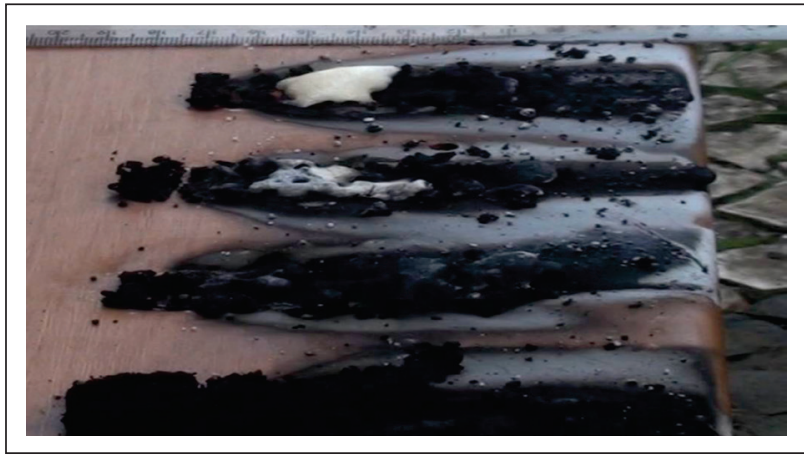

Figure 5. Accumulated residua after the burn process of four samples. carbon residua. It can indicate that the compounds mixture was not exactly homogenous in these samples.

\section{CONCLUSION}

In this paper, KNSu propellant was processed by cold manufacturing. Although the observed density values were, in general, lower than the ones obtained by fusion process, for the higher applied compression pressures (at about $80 \mathrm{MPa}$ ), results were similar to the ones obtained by Vyverman (1978). It corroborates the feasibility of KNSu cold manufacturing by mechanical press.

From experimental data, it was observed that density $(\rho)$ increases with higher values of the propellant compression pressure $\left(P_{c}\right)$ according to a second-order polynomial function. Moreover, the propellant burning rate $(r)$ also depends on $P_{c}$ according to a second-order polynomial function; however, $r$ decreases with higher values of $P_{c}$.

It was also observed that the product $\rho$ times $r$, which represents the mass flux per unit area, is nearly constant for samples obtained by the cold manufacturing.

\section{ACKNOWLEDGEMENTS}

The authors thank Prof. Juarez Souza de Oliveira and Technician Walderson Klitzke for the use of Ceramic Laboratory dependences at Universidade Federal do Paraná. The authors also acknowledge the financial support of Conselho Nacional de Desenvolvimento Científico e Tecnológico (CNPq), Agência Espacial Brasileira (AEB), by Uniespaço Program, Coordenação de Aperfeiçoamento de Pessoal de Nível Superior (CAPES) and the referees by their suggestions. The first four authors receive scholarships supported by CAPES. The last author receives a scholarship supported by CNPq.

\section{REFERENCES}

Aravind, M., Jerin, J., Rariprasad., V., Ganesh, B.K., Aswin, C. and Kumar, V.R.S., 2013, "In-house Manufacture of Variable Burning Rate Propellant Bangles for Nozzleless Propulsion", Proceedings of the International Conference on Aerospace, Mechanical, Automotive and Materials Engineering, Paris, France.
Douglass, H.W., Collins, J.H. and Keller, R.B., 1972, "Solid Propellant Design and Internal Ballistics", NASA, SP-8076.

Fordham, S., 1980, "High Explosives and Propellants", 2nd edition, Pergamon Press, Oxford, UK. 
Marchi, C.H., Besozzi, B.M., Ciceroni, M. and Hering, S.F., 1990 "Experimental Verification of Nozzle and Propellant Influence on Netuno-R Model-Rocket Performance" (in Portuguese), Federal University of Santa Catarina, Report, Universidade Federal de Santa Catarina, Florianópolis, Brazil.

Moro, D.F., 2013, "Personal communication to C.H. Marchi", Curitiba.

Nakka, R.A., 1984, "Solid Propellant Rocket Motor Design and Testing", Bachelor of Science Thesis, University of Manitoba, Manitoba, Canada.

Nakka, R.A., 1997, "Richard Nakka's Experimental Rocketry Web Site", Retrieved in March 19, 2014, from http://www.nakka-rocketry.net/

Leslie, S. and Yawn, J., 2002, "Proposion for the Inclusion of KNO3/ Sugar Propellants in the TRA Experimental Rocketry Program", Retrieved in April 9, 2015, from http://www.aeroconsystems. com/motors/sugar_motor/SugarPro_Proposal.pdf

Stancato, F. and Miraglia, J., 1997, "Internal Ballistic Principles: a Methodology and an Experimental Didactic Experimentation", Proceedings of the VI International Mobility Technology Conference and Exhibit, São Paulo, Brazil.

Stancato, F., Racca, J.G.C., Castaldo, F., Carbonari, G., Souza, L.A. and Ballarotti, M.G., 2000, "A 3000 Ns Sugar-Sodium Nitrate Motor Development for Space Education", Proceedings of the 51st International Aeronautical Congress, Rio de Janeiro, Brazil.

Sutton, G.P. and Biblarz, O., 2010, "Rocket Propulsion Elements", John Wiley \& Sons, New Jersey, USA.

Thompson, G., 2014, "How to Make Sugar Rockets", Retrieved in January 13, 2015, from https://www.youtube.com/watch?v=12fR9neVnS8

Vyverman, T., 1978, "The Potassium Nitrate - Sugar Propellant", Report, Belgium.

Wallace, W., 1995, "FMX - the Revised Black Book: a Guide to Field-Manufactured Explosives", Paladin Press, Boulder, USA. 